DOI: https://doi.org/10.47405/aswj.v6i1.161

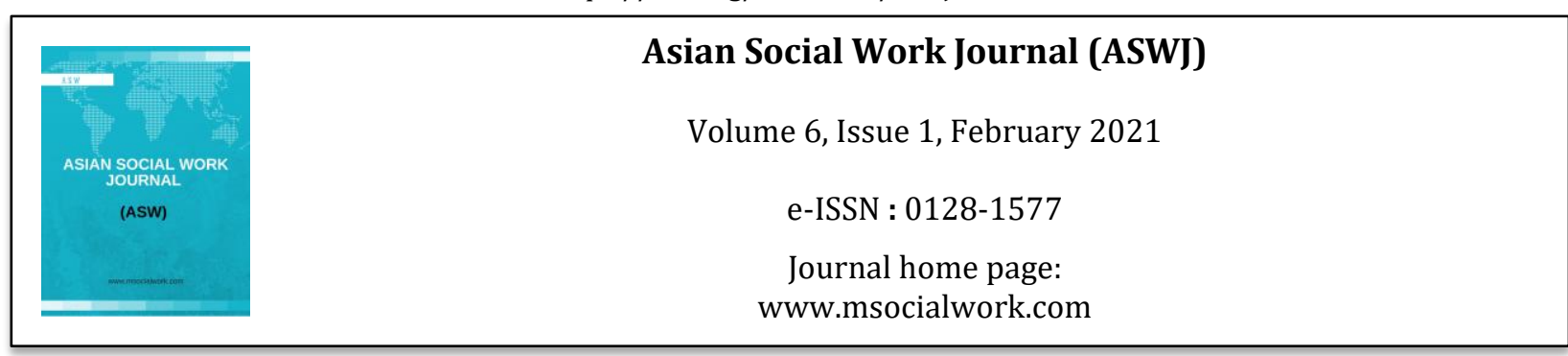

\title{
Social Exclusion of People with Disability in Bangladesh: Dimensions and Challenges
}

\author{
Muahammed Muazzam Hussain ${ }^{1}$ \\ ${ }^{1}$ Shahjalal University of Science \& Technology, Sylhet, Bangladesh \\ Correspondence: Muahammed Muazzam Hussain (muazzam777@yahoo.com)
}

\begin{abstract}
This paper is an outcome of reviewing different dimensions of social exclusion and challenges faced by people with disabilities (PWD) in Bangladesh and suggest some policy guidelines to promote inclusion of PWD into the development process. This paper is based on secondary sources of data and therefore, government, non-government organization's study report, policy documents, journal articles, statistical report, research findings etc. were consulted to collect data and construct the paper. The paper describes the social exclusion of Bangladeshi PWD in the six broad areas e.g. income and assets, employment, education, health and social security, social relationship and recreation. Therefore, some key areas of policy implications are outlined for inclusion of PWD in Bangladesh which include the prospective way to address poverty, adopt active labor market policy, promoting social services and encouraging community based rehabilitation, providing counseling and other support services and utilizing the vision of user involvement etc.
\end{abstract}

Keywords: social exclusion, people with disability, dimensions, challenges, Bangladesh

\section{Introduction}

Globally more than a billion people are living with some sorts of disability and around 190 million people with disability (PWD) experience functional difficulties to maintain their daily activities (WHO, 2018). In the Asia and Pacific region, this figure has been estimated to around 690 million and it may rise in near future due to many factors including climate change related disasters, population aging trends, accidents, long term ill health conditions etc. (ESCAP, 2017). In Bangladesh, approximately 9 percent of the country's total population i.e. more than 15 million people are disabled and nearly half a million people are suffering from multiple disabilities (GED, 2015). It is also shown that people who reported disability, among them 29.6 percent are completely disabled, 43.7 percent have complex disability and 26.7 percent remain partially disabled (BBS, 2019). It is well documented that PWD experience poorer health, low level of educational attainment, less economic opportunities and higher poverty and deprivation in compare with their nondisabled counterpart both at the national and international level (WHO \& WB, 2011). In Bangladesh, they also experience multiple forms of deprivation e.g. poverty, lower levels of educational attainment, labour market participation and community involvement and ultimately falls in a dismal condition characterized by denial of fundamental human rights with isolation and stress. Thus they are often bound to get excluded from adequate resources, income, health care and other basic services (Thompson, 2020; Nokrek et al., 


\section{Asian Social Work Journal (ASWJ), Volume 6, Issue 1, (page 12 - 21), 2021 \\ DOI: https://doi.org/10.47405/aswj.v6i1.161}

2013; Sultana, 2010; Foley \& Chowdhury, 2007; Thomas, 2005; DFID, 2000). However, there are some policy and programs already administered by the government and NGOs for their betterment and reducing social exclusion through increasing accessibility to education, employment, health care and safe-environment, social integration and community based mobilization etc., these are not enough to protect them from social exclusion (NFDD, 2020; WB, GOB, 2004). For example, the Department of Social Service (DSS) under the Ministry of Social Welfare (MOSW) has been working for development of different disadvantage and socially excluded groups including PWD. A means tested welfare services e.g. disability allowance for the PWD and rehabilitation program for the acid burn has been implemented since 2005 and BD TK. 5,000 to TK. 30,000 interest-free micro-credit are provided to acid burn PWD for income generating activities. In addition, a grant of BD TK. 20,000 is paid for medical assistance of poor burn person (DSS, 2020). Despite such positive efforts, PWDs are facing multiple forms of SE as the implementation of policy and services are inadequate to ensure their inclusion in society. Their participation in economic activities, level of educational attainment, utilization of health care and rehabilitation facility remain low and do not cover their physical and emotional requirements etc. This paper investigates the situation of social exclusion of PWD in Bangladesh and identify different dimensions and challenges they face there.

\section{Materials and methods}

This paper addressed the question of: "What are the current situation of social exclusion for people with disability in Bangladesh?" The paper used secondary sources of data i.e. published journal articles, policy documents of government, nongovernmental and international organizations on disability issues to address the research questions. The semi-systematic review strategy was undertaken for conducting a study on a broader issue and diverse group i.e. PWD in Bangladesh and identifying different dimensions and challenges they face. The search term include people with disability, social exclusion, Bangladesh. The process of identifying and appraising all published materials relevant to the topic helped researcher to analyse the SE approach, identify different dimensions and challenges faced by PWD in Bangladesh. Different search engines e.g. the Google scholar, Web of Sciences and Scopus were consulted to collect relevant studies on the specific topic. Initially all abstracts were read and the contents of literatures were assessed and a total of 77 journal articles, reports, policy documents and legislation etc. were finally accepted for review.

\section{Theoretical framework}

Social exclusion (SE) encompasses multiple deprivation and disadvantage condition including the inability to participate ineffectively in socio-economic, political and cultural life (Duffy, 1995). It is often regarded as the breakdown of structural aspects which often disintegrate individuals from society. It generally includes three different discourses e.g. the redistributive discourse (RED) focusing on material deprivation and the moral underclass discourse (MUD) indicating the values and ethical aspects of the people that excluded themselves and the social integrative discourse (SID) highlighting income earning capacity (Lavitas, 1998). By contrast, the Poverty and Social Exclusion Survey in England (2006) has identified four dimensions of social exclusion e.g. impoverishment, exclusion from employment, exclusion from services and social relations etc. Besides these Barnes, M. (2005) pointed out seven dimensions including exclusion to social relationships, cultural and leisure activities, civic amenities, health and social services, community, financing instruments and material resources. This categorization is very good attempt as it covers various aspects that contribute to understand people's multiple form of social exclusion experiences. Despite the significance of this categorization, it is difficult to clarify the SE situation of a particular group of people in a specific socio-economic context. The European Union adopted Lisbon Strategy (2005) for economic growth, employment creation and social development. The focus of this strategy was combat against social exclusion through gaining employment and social objectives and gave emphasis on creating 'better jobs' and reinforce 'social inclusion' and 'social cohesion' (Dieckhoff \& Gallie, 2007). Although, the focus of this approach are straight forward to address the major aspects of SE, it may portray a partial picture of $\mathrm{SE}$ and sometimes connote ambiguity to analyse and use social inclusion and social cohesion aspects interchangeably. Therefore, a better understanding of SE require conceptualization of it as a 


\section{Asian Social Work Journal (ASWJ), Volume 6, Issue 1, (page 12 - 21), 2021 \\ DOI: https://doi.org/10.47405/aswj.v6i1.161}

multidimensional and comprehensive phenomena including social, economic, cultural, political and ecological perspectives and how it occurs in those aspects of the lives of PWD. The SE approach proposed by UN (2007) include multiple dimensions e.g. political, social, economic, culture and technology, voluntary or self- exclusion etc. In the political dimension, it is involved with different civic rights of citizens and the challenges to ensure those rights. By contrast, the socio-economic context, that causes people often fail to participate effectively in their life events include family affairs, inheritance, assets, social, educational, health and protection services etc. The economic exclusion is occurred in the field of economic activities, income and resources manifested as wage discrimination, isolation etc. Apart from that, it is viewed that culture and technology sometimes contribute to form another type of social exclusion as the dominance of certain languages, cultural aspects, application of information technology etc. sometimes create the risk to virtual exclusion. The voluntary or selfexclusion has been identified as another form of exclusion which occurred in the people's life due to different socio- cultural or religious preferences as sometimes it constrains them for effectively enjoy their rights and opportunities. The recent UN World Social Situation report (2016) has examined patterns of social exclusion considering the links between exclusion, poverty and employment trends and also point out that a broader social inclusion framework required to address social exclusion. The report identified inadequate involvement in public, private and community life, prejudice and discrimination etc. as major challenges to combat social exclusion. However, the UN provides a more comprehensive idea on SE, it would be very difficult to measure and analyze some aspects of SE e.g. voluntary withdrawal of individual or groups from social participation or impact of culture and technology as how it create SE for PWD in a developing country like Bangladesh. For the purposes of paper, social exclusion of PWD are analysed in the following aspects: income and resources, employment, health and social services, education and training, exclusion to social relationship and exclusion to recreation.

\section{Results and discussion}

\section{Social Exclusion dimensions and challenges}

\section{Exclusion from income and resources}

The PWD in Bangladesh are live in dismal economic condition characterized by social exclusion and disadvantage. Majority of them are living under the threshold of poverty and get excluded from adequate income and resources. Despite, currently more than 1.5 million PWDs are getting BDT 13905 million annually, the monthly amount of benefit is BDT 750 per month (i.e. equivalent to \$ 8.82) which can hardly meet their health and social care needs (DSS, 2020). A growing number of studies on disability issue (Thompson, 2020; Buettgen et. al., 2015, Davis, 2016, Sultana, 2010, DFID, 2000) point out that PWD experience extensive economic hardships and lack of access to resources, assets and faces discrimination and impoverishment. It has been clarified out that disability creates much pressure on PWD and family poverty and social inequality poses great challenge to them. For example, they need to spend much money to carry out health care expenses e.g. doctor's fee, treatment, diagnosis, transport etc. related to their physical impairment. In many cases, they cope with the situation by selling productive assets including agricultural land, livestock or taking loan from NGO and informal sources and therefore, disability increases the risk of poverty and exclusion. It is shown that there exist some disparity among the general people and PWD over the means of income (Thompson, 2020). Studies also point out that poverty causes morally and socially devastating impact on PWD. Their families also experience multiple disadvantaged conditions including lack of social solidarity and equitable access to resources, social exclusion and stigma which in turn reduces their capacity to overcome poverty (Foley \& Chowdhury, 2007). Masud \& Saha (2014) also pointed out that although the GOB introduced safety net programs for poverty alleviation of different vulnerable groups including PWD, the programs are facing many challenges e.g. administrative complexity, high cost, lack of proper selection, weak governance, corruption less transparency and accountability etc. PWD also face difficulties to get access into microfinance institutions e.g. discrimination and less access to credit as in majority cases, service providers undermine their capacity to engage in income generating activities and lack of willing and trust to serve them (Sarker, 2015). 


\section{Exclusion from employment}

Despite the governmental effort to bring disability issue in the national development agenda and emphasis on holistic approach of development e.g. disability detection survey, employment creation, improving the living condition of PWD etc., critiques argue that employment creation and community based rehabilitation does not get much success. However, often it is argued that the existent Disabilities Act, 2013 ensures enforcement measures to remedy discrimination in employment, in reality legislation fails to remove SE in employment of PWD due to internalized misconceptions about their capacity and women face barriers to get a job due to cultural norms (Thompson, 2020). Other studies (Tabassum et al. 2019, Ali, 2014, Tareque et al. 2014, Morgon \& Polack, 2014, Alam, et al., 2005) also point out that PWD in Bangladesh are facing exclusion from employment in mainstream job market activities and the estimated loss could be US \$ 891 million per year. These studies also identified a number of factors including lack of appropriate education and essential professional skills, vocational training opportunity, human resources development training initiatives etc. which causes their exclusion from employment. Majority of PWD do not get adequate professional support and therapeutic services to engage in formal and informal sector employment. Many employers are also reluctant to recruit PWD in their businesses and other formal sector employment for absence of good work condition and positive community attitude towards disability (CRPD, 2019; Jalil, 2012, NFOWD, 2005). Majority of PWD in Bangladesh are engaged in manual work (e.g. earth digging, water supply, farm and non-farm labour etc.) and experience wage and gender based discrimination (Davis, 2016, NGDO, NCDW, BLAST, 2015, Nokrek et al. 2013). These studies also identified some challenges for mainstreaming employment of PWD including motivational factors, increasing community sanctions and approval, overcoming cultural barriers, family cooperation etc. (Dhar \& Farzana, 2017, NHRC Bangladesh, 2013, Ferdaush and Rahman, 2011, UNICEF, 2010).

\section{Exclusion from health and social services}

The health sector of Bangladesh currently facing challenges e.g. ensuring health service delivery and access to skilled birth attendance, coverage of antenatal care and lack of trained physicians, nurses, pathologists, adequate number of hospital beds etc. which severely affect the satisfaction of patients including PWDs (BBS 2019; Hussain \& Raihan, 2015; El Arifeen et al., 2013). They face additional health challenges with their physical impairments e.g. diabetes, hypertension, depression etc. which requires extra care for some diseases including diarrhea, respiratory infections, viral fevers, malaria etc. (Talukder et al., 2018; Verma \& Namdeo, 2016). Despite such health vulnerability, they experience exclusion from health and social care services due to poverty and scarcity of resources. For example, in a study it is shown that 68.9 per cent of PWD did not get any help from social or developmental organizations. Since, most of the health care services, physiotherapy and assistive device centers are city based, managing health cost remain a major challenge for majority PWD living in rural areas (Venkata, 2018, Sultana et al., 2017, NOFOWD, 2005). The other challenges include scarcity of professionals e.g. physiotherapist, occupational-therapists, specialized services etc. These shortages of health care workforce also affect health care services for PWD in the country (MHFW, 2016; GED, 2015; WHO, 2014; NHP, 2011). The psychological and mental services for PWD is also very limited due to shortage of trained physicians, psychiatric professionals, governmental and nongovernmental investment and negative community attitude involved with receiving such services (Islam and Biswas, 2015).

The government safety-net programs has been considered as an important social security services for poor vulnerable people like PWD in Bangladesh. But the coverage of the safety net programs is very low among the extreme poor with disability. Recent studies (Kidd, 2017, Haider \& Mahamud, 2017) also point out that exclusion of PWD is occurred from the stage of identification and registration of beneficiaries to implementation \& evaluation stage. The coverage and amount of safety net programs are not consistent to enhance their capacity to achieve health and other care services. In addition, PWD also face some barriers in accessing to other basic services e.g. water and sanitation services. The challenges include lack of assistive devices, washroom facility, communication technology, less friendly social environment etc. (Venkata, 2018). 


\section{Exclusion from education and training}

Since, the Education policy of Bangladesh (2010) focuses on special education, inclusive education for children with physical impairment and intellectual disability, the Social Welfare Directorate has administered integrated education program in 64 district level schools for the visually handicapped children (DSS, 2020). But the services are inadequate to include the vast majority of the children, youth and PWDs. The major challenges for implementing inclusive education include poverty, gender inequality, ethnicity, regional disparity and negative aspects of climate change and disaster etc. (Begum et al. 2019). A number of growing studies (UNESCO, 2020; Male \& Wodon, 2017; UNICEF, 2009, NOFOWD, 2005) also point out that PWD including children with disabilities in Bangladesh experience limited opportunities to study at educational institutes and identify a number of factors e.g. absence of accessive environment, inclusive teaching curriculum, methodologies, etc. that causes to limit the opportunities. The major challenges to make expansion of educational opportunities include lack of introducing fundamental training of teachers on teaching young and adult with disabilities, implementation of government policies and legislation regarding disability issue etc. For example, disability friendly facilities are absent at schools, market, hospitals and roads. Lamichhane \& Kawakatsu (2015) also point out that student's educational attainment is adversely affected by disability and suggests for adopting disability-inclusive poverty reduction strategies to increase positive learning outcome. In Bangladesh, there is hardly found any integrated approach considering the alternative communication methods to prepare them to accommodate with mainstream education. Besides these, lack of understanding among practitioners and classroom teachers to apply the integrated approach within the socio- economic context of Bangladesh remain a big challenge to address social exclusion in education sector (Ahsan \& Mullick, 2013, Malak et al., 2013).

\section{Exclusion to social relationship}

Disability in Bangladesh is seen as curse and sometimes it creates an embarrassment for whole family which poses a risk to social exclusion of PWD. PWD face strain relationship with family, relatives and members of the community. Even inside the family their siblings and parents feel shame and want to conceal their disabled identity due to society's negative attitude (UNICEF, 2009, Hussain, 2008, Titumir and Hossain, 2005). Studies (Davis, 2016, Sultana, 2010, GOB, IMF, 2005) also point out that community people use derogatory terms for people who are deaf, unable to speak, or have mobility impairments which prevent them to participate in social events e.g. festivals and market places etc. People with intellectual disabilities are particularly vulnerable to being taunted and attacked in public places. They can hardly enjoy friendly environment, cooperation, mental and financial support to lead a productive life. Even inside the family they do not get importance as family members thought them unproductive (GED, 2015; Davis, 2016; Sultana, 2010). They perceive that they are given less importance in the household level as well as society which in turn, resulted to make them confined within home environment and withdraw from social affairs. It is shown that PWDs have experience a complete isolation, social exclusion and lead a like an inactive member of family and society. The vulnerability is higher for women with disabilities as they are discouraged to get married and have no right to choose their partners (NGDO, 2019; Maloni et al, 2010; Hosain, \& Chatterjee, 1998). They are not actively engaged in public sector programs designed to promote sexual and reproductive health. The programs lack effective and appropriate measures to be undertaken to eliminate exclusion and discrimination of PWD (NGDO, 2019).

\section{Exclusion from recreation}

PWD in Bangladesh are excluded from recreation activities both in urban and village areas. In a recent report (CRPD, 2019) it is shown that PWD face barriers in accessing to sport centres, tourist spots, exhibition places, amusements places, parks, public libraries etc. Due to physical impairments and other structural barriers e.g. transport design, financial constraint, lack of personal carer etc., they cannot avail the opportunity to visit park, amusement centre and other cultural places. The social barriers including social stigma and negative community attitude they can hardly participate in social and cultural events like marriage ceremony, religious and other cultural festivals etc. The other challenges include shortage of domestic manufacturers for sport, recreational and educational equipment causes high cost 
of materials not affordable to PWDs. The scarcity of fund also prevent different public organizations and NGOs to organise sports, game and other recreational services for PWD. However, the government youth departments and other organizations arrange some sports and cultural events for them, critiques point out that they offer limited programmes and only a few number of PWD living in urban areas get the opportunity to enjoy recreation services (CRPD, 2019). In majority cases, they depend on television and satellite programs, but those programs hardly focus on their needs or choices. Negative community attitude, financial and structural obstacles poses threat to their inclusion in recreation activities.

\section{Conclusion and policy implications}

This paper highlights multiple dimensions of exclusion, disadvantages and challenges faced by PWD in Bangladesh. They experience economic hardships and impoverishment as they are excluded from adequate income and resources, assets. They are deprived from getting appropriate education and training opportunities, positive work environment, low income etc. and face diverse challenges including engage in manual labour, employer's negative attitude, wage and gender based discrimination etc. The data also highlight a gloomy picture of exclusion from health and social services e.g. limited scope of medical or rehabilitation assistance, lower provision of physiotherapy and assistive device services, managing health cost etc. This paper also concerns the limitation of recreation and entertainment facilities and the risk of exclusion to social relationship as they live in unfriendly environment with limited cooperation, ill treatment and neglect. However the paper provides some valuable information and insights on the different forms of social exclusion as PWD experience in the socio-economic, cultural and environmental context of Bangladesh, more qualitative and quantitative researches are required to gain in depth knowledge about the issue and explore the interlink between disability and social exclusion. Although the national policy on disability in Bangladesh put much emphasis on creating opportunity for betterment of PWD, the GOs and NGOs do not grow much effort to carry out different services to address their basic human needs. A prospective way to address poverty would involve creating small business activities for them, ensure access to credit, protection of productive assets, access to training and other forms of support for small businesses etc. Active labor market policy should be redesigned to promote the education and employability of PWD, provision of getting microcredit without interest and many other opportunities e.g. exempt from taxation, work incentives etc. For Promotion of inclusive education, it is necessary to ensure appropriate training facilities of teachers, curriculum redesign, study materials and provision of technological tools and equipments etc. for PWD to increase their employability and livelihood. Promoting social services and encouraging community based rehabilitation should be a key strategy for prevention of disability, raising consciousness among society people to realize the potentiality of PWD and their involvement in social, economic, cultural and religious activities. The GOB should take steps to provide counselling and other support services to increase family's ability to provide care of PWD. The GOB, local government, NGOs and other voluntary sector development partners should promote recreation, community participation and other user involvement initiatives to challenge current exclusions and discriminations faced by PWD.

\section{References}

Ahsan, M. T., \& Mullick, J. (2013). The journey towards inclusive education in Bangladesh: Lessons learned. Prospects, 43(2), 151-164.

Alam, K.J., Bari, N. and Khan, M.A., (2005). Community based rehabilitation practices and alleviation of poverty of people with disabilities in Bangladesh, The National Forum of Organizations Working with the Disabled (NOFOWD), Dhaka.

Ali, Z. (2014). Economic costs of disability in Bangladesh. The Bangladesh Development Studies, 37(4), 17-33.

Bangladesh Bureau of Statistics (2015). Disability in Bangladesh: Prevalence and Pattern, Population Monograph. Vol. 5. Ministry of Planning, Statistics and informatics Division. Govt. of the Peoples Republic of Bangladesh. 


\section{Asian Social Work Journal (ASWJ), Volume 6, Issue 1, (page 12 - 21), 2021 DOI: https://doi.org/10.47405/aswj.v6i1.161}

Bangladesh Bureau of Statistics (2019). Report on Bangladesh sample vital statistics 2018. Statistics and Informatics Division, Ministry of Planning, Govt. of the Peoples Republic of Bangladesh.

Bangladesh, U. N. I. C. E. F. (2014). Situation analysis on children with disabilities in Bangladesh. UNICEF Bangladesh, Bangladesh.

Barnes, C. (2005). The social model of disability: A sociological phenomenon ignored by sociologists in T. Shakespeare (ed.), The Disability Reader: Social Science Perspective. London.

Begum, H. A., Perveen, R., Chakma, E., Dewan, L., Afroze, R. S., \& Tangen, D. (2019). The challenges of geographical inclusive education in rural Bangladesh. International Journal of Inclusive Education, 23(1), 7-22.

Buettgen, A., Gorman, R., Rioux, M., Das, K., \& Vinayan, S. (2015). Employment, poverty, disability and gender: A rights approach for women with disabilities in India, Nepal and Bangladesh. In Women's Mental Health (pp. 3-18). Springer, Cham.

CRPD Alternative Report Platform, Bangladesh. (2019). Alternative report on the status of implementation of the convention on the rights of persons with disabilities in Bangladesh. Retrieved from: https://www.blast.org.bd/content/report/Alternative-Report-NGDO-2019.pdf Date: $13-02-2020$.

DFDD. (2020) National Foundation for Development of the Disabled Persons. Government of the Peoples' Republic Bangladesh, Retrieved from: from:http://www.jpuf.gov.bd/site/page/46387ad8-3761-4023-a8c7-83caeb01c8b8/- on: 08-082020.

DFID. (2000). Disability, Poverty and Development, Department of International Development, London: UK

Dhar, S., \& Farzana, T. (2017). Entrepreneurs with disabilities in Bangladesh: an exploratory study on their entrepreneurial motivation and challenges. European Journal of Business and Management, 9(36), 103-114.

Dieckhoff, M., \& Gallie, D. (2007). The renewed Lisbon Strategy and social exclusion policy. Industrial Relations Journal, 38(6), 480-502.

DSS. (2020). Department of Social Services. Government of the Peoples Republic of Bangladesh. Retrieved from: http://www.dss.gov.bd/site/page/a8c37128-200f-4cfe-98361d1ac7737e91/Allowance-for-PWD's on: 08-02-2020.

Duffy. (1995). Social Exclusion and Human Dignity in Europe, Council of Europe.

El Arifeen, S., Christou, A., Reichenbach, L., Osman, F. A., Azad, K., Islam, K. S. \& Peters, D. H. (2013). Community-based approaches and partnerships: innovations in health-service delivery in Bangladesh. The Lancet, 382(9909), 2012-2026.

ESCAP. ( 2017). Disability in Asia and the Pacific: The Facts - 2017, Midpoint Review edition. Retrieved from: https://www.unescap.org/sites/default/files/Disability_The_Facts_2.pdf. Date: $13-02-2020$

Ferdaush and Rahman, (2011). cited in Quinn M.E., Hunter C.L., Ray S., Quadir M.M., Sen K., Cumming R. (2016). The double burden: Barriers and facilitators to socioeconomic inclusion for women with disability in Bangladesh. 27(2). doi 10.5463/DCID.v27i2.474. http://dcidj.org/article/view/474 Accessed on: 10-02-19.

Foley, D., \& Chowdhury, J. (2007). Poverty, social exclusion and the politics of disability: Care as a social good and the expenditure of social capital in Chuadanga, Bangladesh. Social Policy \& Administration, 41(4), 372-385.

General Economics Division. (2015). The $7^{\text {th }}$ Five Year Plan, (2016-2020). Accelerating Growth, Empowering Citizens. General Economics Division, Planning Commission, Government of the People's Republic of Bangladesh, Dhaka.

GOB, IMF. (2005). Bangladesh: Unlocking the Potential, National Strategy for Accelerated Poverty Reduction.

Haider, M. Z., \& Mahamud, A. (2017). Beneficiary Selection and Allowance Utilization of Social Safety Net Programme in Bangladesh. Journal of Human Rights and Social Work, 2(1-2), 4551.

HI \& NFOWD (2005). Ability through accessibility: towards a barrier free environment for persons with disability, Handicap International and National Forum of Organizations Working with the Disabled, Dhaka. 
DOI: https://doi.org/10.47405/aswj.v6i1.161

Hosain, G. M., \& Chatterjee, N. (1998). Health-care utilization by disabled persons: a survey in rural Bangladesh. Disability and rehabilitation, 20(9), 337-345.

https://extranet.who.int/nutrition/gina/en/node/25874.

Hussain, A. (2008). Report on women with disabilities in Bangladesh, Social Assistance and Rehabilitation for the Physically Vulnerable (SARPV). Bangladesh. Available at: http://wwda.org.au/wp-content/uploads/2013/12/bangladeshwwd1.pdf Accessed on: 17-02-19

Hussain, M. M., \& Raihan, M. M. H. (2015). Patients' satisfaction with public health care services in Bangladesh: Some critical issues. Malaysian Journal of Medical and Biological Research, 2 (2), 105-126.

Islam, A., \& Biswas, T. (2015). Mental health and the health system in Bangladesh: situation analysis of a neglected domain. Am J Psychiatry Neurosci, 3(4), 57-62.

Jalil, M. (2012). Disabled People's Access to Public Sector Employment in Bangladesh: Why So Little Changes?. OIDA International Journal of Sustainable Development, 3(9), 87-92.

Jehoel- Gijsbers and Vrooman, (2008). cited in Tong, H. M., Lai, D. W., Zeng, Q., \& Xu, W. Y. (2011). Effects of social exclusion on depressive symptoms: elderly Chinese living alone in Shanghai, China. Journal of cross-cultural gerontology, 26(4), 349-364.

Kidd, S. (2017). Social exclusion and access to social protection schemes. Journal of Development Effectiveness, 9(2), 212-244.

Lamichhane, K., \& Kawakatsu, Y. (2015). Disability and determinants of schooling: A case from Bangladesh. International Journal of Educational Development, 40, 98-105.

Lavitas (1998). The Inclusive Society, Basingstoke: Macmillan.

Lena, M., Banks, L.M. and Polack, S. (2014). The Economic Costs of Exclusion and Gains of Inclusion of People with Disabilities: Evidence from Low and Middle Income Countries, International Centre for Evidence in Disability, London School of Hygiene \& Tropical Medicine. Retrieved from: http://disabilitycentre.lshtm.ac.uk/files/2014/07/Costs-of-Exclusionand-Gains-of-Inclusion-Report.pdf on: 17-02-19.

Malak, S., Begum, H. A., Habib, A., Shaila, M., \& Moninoor, M. (2013). Inclusive Education in Bangladesh: Policy and Practice. In Joint AARE Conference, Adelaide (pp. 1-15).

Male C, Wodon Q. (2017). Disability gaps in educational attainment and literacy. The Price of Exclusion: Disability and Education Series. World Bank and GPE, Washington, DC http://documents.worldbank.org/curated/en/396291511988894028/Disability-gaps-ineducational- attainment-and-literacy

Maloni, P.K., Despres, E.R., Habbous, O., Primmer, A.R., Slatten J.B. Gibson, B.E. \& Landry, M.D. (2010). Perceptions of disability among mothers of children with disability in Bangladesh: Implications for rehabilitation service delivery, Disability and Rehabilitation. 32(10):845-854.

Masud-All-Kamal, M., \& Saha, C. K. (2014). Targeting social policy and poverty reduction: The case of social safety nets in Bangladesh. Poverty \& Public Policy, 6(2), 195-211.

MHFW. (2016). Health, Nutrition and Population Strategic Investment Plan (HNPSIP) 2016-2021. English version accessed via WHO.

Morgon Banks, L., \& Polack, S. (2014). The economic costs of exclusion and gains of inclusion of people with disabilities: Evidence from low and middle income countries. International Centre for Evidence in Disability, London School of Hygiene \& Tropical Medicine.

National Grassroots and Disabilities Organization, (NGDO). National Council for Women with Disabilities, (NCDW). Bangladesh Legal Aid and Services Trust, (BLAST). (2015). Current status of the rights of persons with disabilities in Bangladesh: Legal and Grassroots Perspective, Dhaka.

NHRC Bangladesh. (2013). Institutional, functional and financial independence need to be strengthened, Ain o Salish Kendra (ASK), Dhaka Available at: http://www.askbd.org/ask/wpcontent/uploads/2014/03/NHRC-Capacity-Assessment-ASKs-Written-Submission-December20131 Accessed: 17.02.19

NOFOWD. (2005) cited in Alam, K.J., Bari, N. and Khan, M.A., (2005). Community based rehabilitation practices and alleviation of poverty of people with disabilities in Bangladesh, The National Forum of Organizations Working with the Disabled, Dhaka.

Nokrek, P., Alam, M.A. and Ahmed M. (2013). Livelihood challenges for extremely poor disabled people in the southwest coastal region of Bangladesh, working paper 12, Shiree, Dhaka. 


\section{Asian Social Work Journal (ASWJ), Volume 6, Issue 1, (page 12 - 21), 2021 \\ DOI: https://doi.org/10.47405/aswj.v6i1.161}

Peter Davis, (2016). Exploring the Links between Poverty and disability in Rural Bangladesh, Chronic Poverty and advisory Network. Accessed: 12-02-2019

Sarker D. (2015). Inclusion of disabled people in microfinance institutions: where does Bangladesh stand? International Journal of Innovation and Economic Development 1(1) https://researchleap.com/inclusion-of-disabled-people-in-microfinance-institutions-where-doesbangladesh-stand/

Social Exclusion Unit. (2006). The Poverty and Social Exclusion Survey in England, HMSU: London.

Sultana, M., Mahumud, R. A., \& Sarker, A. R. (2017). Burden of chronic illness and associated disabilities in Bangladesh: Evidence from the Household Income and Expenditure Survey. Chronic diseases and translational medicine, 3(2), 112-122.

Sultana, Z. (2010). Agony of persons with disability: A comparative study of Bangladesh, Journal of Politics and Law, 3(2), 212-221.

Tabassum, I., Saptok, J. A., Kabir, K. R., \& Tabassum, E. (2019). Investigating the Accessibility of Physically Disabled Individuals in Corporate Offices: A Case of Dhaka City. International Journal of Civil and Architectural Engineering, 13(3), 164-168.

Talukdar, J. R., Mahmud, I., \& Rashid, S. F. (2018). Primary health care seeking behaviour of people with physical disabilities in Bangladesh: a cross-sectional study. Archives of Public Health, $76(1), 43$.

Tareque, M. I., Begum, S., \& Saito, Y. (2014). Inequality in disability in Bangladesh. PLoS One, 9(7).

The Danish Bilharziasis Laboratory for the World Bank, Government of Bangladesh. (2004). Disability in Bangladesh: A Situation Analysis. Retrieved from: https://asksource.info/sites/all/modules/pubdlcnt/pubdlcnt.php?fid=1450

The Poverty and Social Exclusion Survey in England. (2006). cited in Palmer G., MacInnes T. and Kenway P. (2006). Monitoring poverty and social exclusion. Joseph Rowntree Foundation, UK. Retrieved from: https://www.jrf.org.uk/sites/default/files/jrf/migrated/files/1815-poverty-uk2006.pdf on: 17-02-19.

Thomas, P. (2005). Disability, poverty and the millennium development goals: Relevance, challenges and opportunities for DFID, Disability, Knowledge and Research, pp1-32.

Thompson S. (2020). Bangladesh Situational Analysis. Disability Inclusive Development.

Titumir R.A. and Hossain, J. (2005). Disability in Bangladesh: Prevalence, knowledge, attitudes and practices, Unnayan Onneshan (The Innovators), Centre for Research and Action on Development, Dhaka.

Tong, H. M., Lai, D. W., Zeng, Q., \& Xu, W. Y. (2011). Effects of social exclusion on depressive symptoms: elderly Chinese living alone in Shanghai, China. Journal of cross-cultural gerontology, 26(4), 349-364.

UNESCO. (2020). Global Education Monitoring Report 2020: Inclusion and education: All means all. UNESCO, Paris https://en.unesco.org/gem-report/report/2020/inclusion

United Nations (UN). (2007). Literature review on social exclusion in the ESCWA region, Economic and Social Commission for Western Asia, New York.

United Nations International Children's Emergency Fund. (2009). Situation Assessment and analysis of children and women in Bangladesh. UNICEF: New York.

United Nations International Children's Emergency Fund. (2010). Women and Girls in Bangladesh. UNICEF: New York.

United Nations. (2016). Leaving No One Behind: The Imperative of Inclusive Development. Report on the World Social Situation 2016.

Venkata S. Murthy Gudlavalleti. (2018). Challenges in accessing health care for people with disability in the South Asian context: A review.

Verma S, Namdeo M. (2016). Health related quality of life and perceived quality of health care among people with physical disabilities in Bangladesh. Proceeding of the 2nd International Conference
http://tiikmpublication.com/Proceedings/doi/icoph.2016.2112.pdf

WHO. (2011). World Report on disability. Retrieved from: https://www.who.int/disabilities/world_report/2011/report.pdf on 22-02-19.

WHO. (2014). Global Health Workforce Statistics, 2014 Update. Geneva: World Health Organization. Saatavissa, 30, 2016. 
Asian Social Work Journal (ASWJ), Volume 6, Issue 1, (page 12 - 21), 2021 DOI: https://doi.org/10.47405/aswj.v6i1.161

WHO. (2018). Disability and health. Retrieved from: https://www.who.int/en/news-room/factsheets/detail/disability-and-health on 15-02-2020. 